Article

\title{
The Pleiotropic Antibacterial Mechanisms of Ursolic Acid against Methicillin-Resistant Staphylococcus aureus (MRSA)
}

\author{
Chao-Min Wang, Yun-Lian Jhan, Shang-Jie Tsai and Chang-Hung Chou * \\ Research Center for Biodiversity, China Medical University, Taichung 40402, Taiwan; \\ wangchaomin@mail.cmu.edu.tw (C.-M.W.); ah_giu@yahoo.com.tw (Y.-L.J.); csungjay@yahoo.com.tw (S.-J.T.) \\ * Correspondence: choumasa@mail.cmu.edu.tw; Tel.: +886-4-2205-3366 (ext. 1633) \\ Academic Editor: Peter J. Rutledge \\ Received: 2 June 2016; Accepted: 30 June 2016; Published: 7 July 2016
}

\begin{abstract}
Background: Several triterpenoids were found to act synergistically with classes of antibiotic, indicating that plant-derived chemicals have potential to be used as therapeutics to enhance the activity of antibiotics against multidrug-resistant pathogens. However, the mode of action of triterpenoids against bacterial pathogens remains unclear. The objective of this study is to evaluate the interaction between ursolic acid against methicillin-resistant Staphylococcus aureus (MRSA); (2) Methods: The ability of ursolic acid to damage mammalian and bacterial membranes was examined. The proteomic response of methicillin-resistant $S$. aureus in ursolic acid treatment was investigated using two-dimensional (2D) proteomic analysis; (3) Results: Ursolic acid caused the loss of staphylococcal membrane integrity without hemolytic activity. The comparison of the protein pattern of ursolic acid-treated and normal MRSA cells revealed that ursolic acid affected a variety of proteins involved in the translation process with translational accuracy, ribonuclease and chaperon subunits, glycolysis and oxidative responses; (4) Conclusion: The mode of action of ursolic acid appears to be the influence on the integrity of the bacterial membrane initially, followed by inhibition of protein synthesis and the metabolic pathway. These findings reflect that the pleiotropic effects of ursolic acid against MRSA make it a promising antibacterial agent in pharmaceutical research.
\end{abstract}

Keywords: methicillin-resistant Staphylococcus aureus (MRSA); ursolic acid; two-dimensional gel electrophoresis (2DE)

\section{Introduction}

Pentacyclic triterpenoids, one of the most abundant natural products existing terrestrial plants, have been demonstrated to exhibit various pharmacological activities, such as hepatoprotective, anti-inflammatory, antioxidant, and anticancer effects [1-4]. The plant-derived chemicals enhancing the bacteria's susceptibility to other antibiotics have increasingly been paid more attention. Additionally, pentacyclic triterpenoids such as betulinic acid, imberbic acid, oleanolic acid, ursolic acid and zeylasteral have also been reported to possess antimicrobial activity [5-7]. Moreover, ursolic acid showed a synergistic effect with ampicillin and tetracycline against both Bacillus cereus and Staphylococcus aureus [5]. The potentiality of ursolic acid in synergistic effects with antibiotics to enhance the antibacterial activity of $\beta$-lactams can constitute a valuable agent for therapeutic application [5]. However, there are limited reports involving the antibacterial mechanism on pathogenic bacteria for pentacyclic triterpenoids.

Protein expression profiling, which can be constructed by two-dimensional gel electrophoresis (2DE), is an excellent approach to demonstrate the pattern of proteins expressed; 2DE can also be applied to show to what extent each single protein is expressed in different environmental conditions. 
In S. aureus and B. subtilis, gel-based proteomics is also a useful approach for visualizing the responses of bacteria to stress and starvation [8]. With the advantage of mass spectrometry (MS), the 2D gel approach combined with MS for protein identification may facilitate a broad view on the physiological state of the bacterial cell, allowing us to study the cellular response of bacteria to classical antibiotics and to identify the modes of action of novel compounds [9]. Previous reports indicated that the antibacterial mechanism of the pentacyclic triterpenoids was shown to be involved in regulating the expression of genes associated with peptidoglycans and virulence factors in bacteria [10]. Therefore, the impact of ursolic acid on membrane integrity was conducted in this study. Furthermore, an attempt is also made to understand the antibacterial mechanism of ursolic acid using 2D proteomic analysis. Comparative proteome analyses were conducted to investigate whether or not the proteomic response would reveal marker proteins in ursolic acid treatment. Based on the correlation of these marker proteins with their functional properties, the antibacterial mechanisms of ursolic acid could be proposed.

\section{Results}

\subsection{Effects of Antibiotics and Ursolic Acid on Bacterial and Mammalian Membrane Viability}

Rapid bactericidal activity is a feature that common to antibacterial agents acting on bacteria by compromising the integrity of the cytoplasmic membrane. To examine whether ursolic acid acts on bacterial membranes, we employed the BacLight ${ }^{\mathrm{TM}}$ assay. Previously, we have evaluated the minimum inhibitory concentration (MIC) value of antibiotics and ursolic acid (Figure 1) against methicillin-resistant Staphylococcus aureus (MRSA) [5]. The MIC values of ampicillin, tetracycline and ursolic acid against MRSA were 512, 8 and $64 \mu \mathrm{g} / \mathrm{mL}$, respectively. MRSA were further treated with different concentrations of ursolic acid in mid-exponential phase in this study. Concentrations were chosen that reduced the growth rates to approximately $50 \%$ compared to that of the untreated control culture for membrane viability and proteomic analysis. In this study, MRSA exposed to $4 \times$ of the MIC value of ursolic acid for 60 min retained 49.5\% of their membrane integrity (Table 1). MRSA exposed to $4 \times$ of the MIC value of tetracycline retained $90 \%$ of their membrane integrity, while the known membrane disrupters, such as ampicillin, significantly reduced membrane integrity over the same time period (Table 1). Both ursolic acid and antimicrobial agents caused about a 17\%-19\% loss in erythrocyte integrity, while the known membrane-disrupters sodium dodecyl sulfate (SDS) induced hemolysis (Table 1). The results showed that ursolic acid had little effect on the erythrocyte integrity but reduced the bacterial membrane integrity significantly (Table 1).

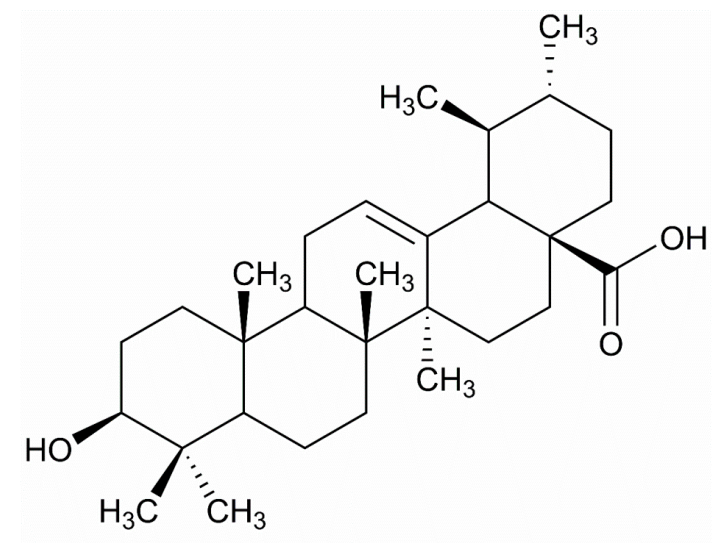

Ursolic acid

Figure 1. Chemical structure of ursolic acid. 
Table 1. Effects of ursolic acid and antibiotics at 4 folds of the MIC on MRSA bacterial membrane.

\begin{tabular}{ccc}
\hline Antimicrobial Compounds & Bacterial Membrane Integrity (\%) & Erythrocyte Integrity (\%) \\
\hline None & $99.4 \pm 7.5^{\mathrm{a}}$ & $101.8 \pm 2.9^{\mathrm{a}}$ \\
5\% SDS & $0 \pm 0^{\mathrm{d}}$ & $0 \pm 00^{\mathrm{c}}$ \\
Ampicillin & $17.9 \pm 0.6^{\mathrm{c}}$ & $81.0 \pm 2.6^{\mathrm{b}}$ \\
Tetracycline & $87.3 \pm 9.6^{\mathrm{a}}$ & $82.2^{\mathrm{a}} \pm 2.3^{\mathrm{b}}$ \\
Ursolic acid & $49.5 \pm 0.8^{\mathrm{b}}$ & $83.0^{\mathrm{b}} \pm 5.0^{\mathrm{b}}$ \\
\hline
\end{tabular}

Different letters represent values that were significantly different at $\alpha=0.05$ level.

\subsection{Effects of Ursolic Acid on Bacterial Protein Synthesis}

Crude proteins from MRSA cultures were extracted and subjected to 2D PAGE for the separation and analysis of protein spots. Approximately 271 protein spots were identified in the control group and 319 spots in the treatment group, ranging in $p \mathrm{I}$ between 4.0 and 10.0, and in molecular weight between 10 and $150 \mathrm{kDa}$ (Figure 2). By matching both images obtained from the control and treatment groups, 200 protein spots were identified in each group. Proteins induced or reduced at least 1.5-fold are referred to as marker proteins. They proved the information about the antibiotic mode of action and reflected the physiological stress conditions of bacteria. Using MALDI-TOF/TOF, 29 protein spots were identified, ranging in $p$ I between 4.3 and 9.7, and in molecular weight between 11 and $133 \mathrm{kDa}$ (Table 2). Changes in protein intensity were statistically evaluated by employing the control value without ursolic acid as the baseline. The protein spots that changed in intensity significantly under ursolic acid treatment are listed in Table 3 and the position of the corresponding protein spots on the MRSA 2D gel is shown in Figure 2. Interestingly, the treatment of MRSA with ursolic acid leads to an induction of phenylalanyl-tRNA synthase and ribosomal protein L21 (Table 2) and a shift in the $p$ I value of ribosomal protein L21 (Figure 1). The elongation factor $G$ and translation initiation factor IF-2 were detected as decreased in this study. No significant change was detected in the production of the transcriptional protein RNA polymerase $\alpha$ and $\beta$ chain. The most notable changes in the protein expression by 2D proteomic analysis indicated that ursolic acid had a marked effect on the expression of important MRSA proteins in folding and degrading the system, such as $\mathrm{ClpC}$ and trigger factor and chaperon proteins. The expression of enzymes involved in glycolysis was found to be decreased, but those involved in the tricarboxylic acid (TCA) cycle showed varying patterns of expression (Table 3). Essentially, glycolysis was repressed by the decreased concentration of Pgk, PdhC and Tkt proteins. The phosphotransferase system was induced by increasing the concentration of PtsI and Crr proteins. Proteins involved in the oxidative response (AhpC) and alcohol dehydrogenase (Adh) were also induced via ursolic acid treatment. Other proteins including the Fe-S cluster assembly protein (SufB), ribose-phosphate pyrophosphokinase (Prs), alkaline shock protein 23 (Asp23) and glyoxal reductase (AKRs) were repressed in this study. Although these uncorrelated proteins do not showed rational insights into the antibacterial mechanism, they still serve as specific markers, as they are reproducibly reduced after ursolic acid treatment.

As shown in Figure 3, details of 2D gels depicting 16 specific marker proteins were presented. Proteins induced or reduced at least 1.5 -fold are referred to as marker proteins. In response to translational interpretation, translation initiation factor IF-2 ( InfB) was reduced while the phenylalanyl-tRNA synthase subunit beta (PheT) and 50S ribosomal protein L21 (RplU) were induced. In addition, the protein folding and degrading system (ClpC, RnaseJ), the bacterial phosphoenolpyruvate sugar phosphotransferase system (PtsI and Crr proteins), and the oxidative response (Ahp C) were all induced in ursolic acid treatment. 
control

pH 3

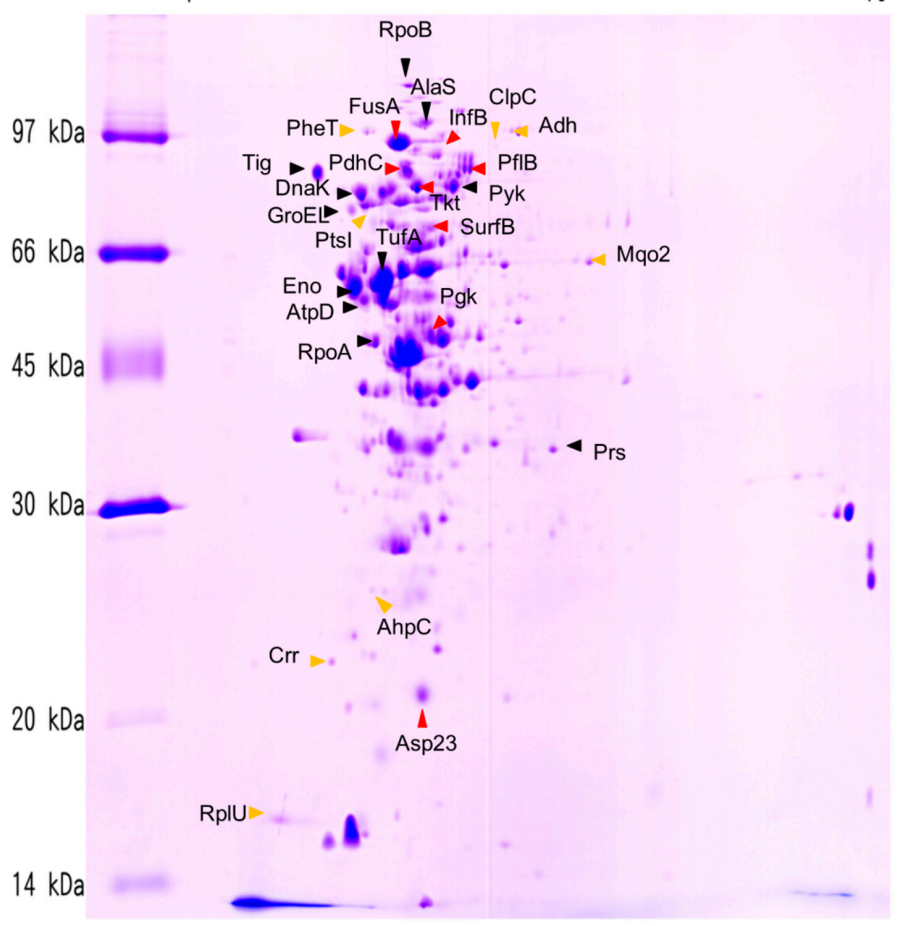

(a)

treatment

pH 3

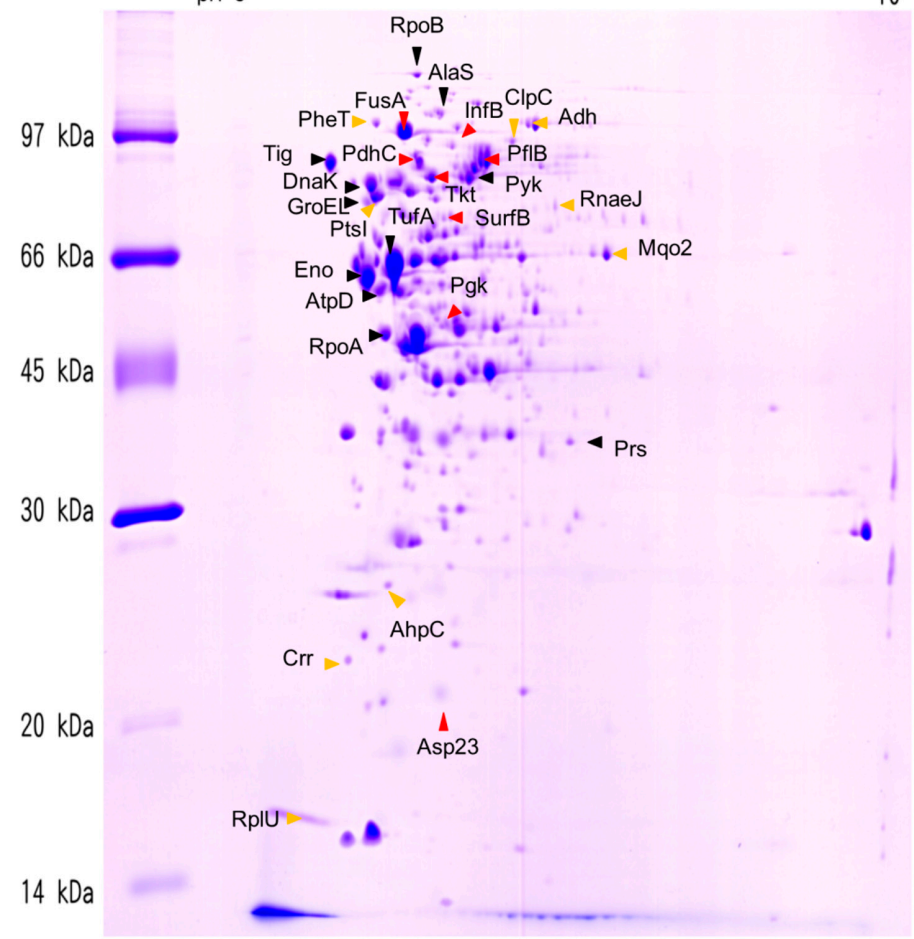

(b)

Figure 2. The 2D gel showing spots of interest with proteins isolated from untreated MRSA (a) and proteins from ursolic acid-treated MRSA (b); 2D-PAGE was used to separate cytoplasmic proteins in the $p \mathrm{I}$ range of three to 10 according to their $p$ Is and molecular weight. Proteins induced by the ursolic acid appear yellow, repressed proteins appear red, and proteins with no significantly changes are indicated as black. 
Table 2. Proteins of MRSA identified by LC-MS/MS fingerprints in treatment of ursolic acid.

\begin{tabular}{|c|c|c|c|c|c|}
\hline Protein & Protein Name & Accession No. & $p \mathbf{I}$ & M.W. & Coverage $(\%)$ \\
\hline Adh & Alcohol dehydrogenase & gi| 487362910 & 5.63 & 94,886 & $30 \%$ \\
\hline AhpC & $\begin{array}{l}\text { Alkyl hydroperoxide reductase } \\
\text { subunit } C\end{array}$ & gi | 445974926 & 5.06 & 20,846 & $38 \%$ \\
\hline AKRs & glyoxal reductase & gi| 446374225 & 5.09 & 31,261 & $14 \%$ \\
\hline AlaS & Alanyl-tRNA synthase & gi| 446656721 & 5.00 & 98,479 & $13 \%$ \\
\hline Asp23 & alkaline shock protein 23 & gi| 446137381 & 5.27 & 19,060 & $27 \%$ \\
\hline AtpD & ATP synthase subunit beta & gi $\mid 446433275$ & 4.71 & 51,382 & $40 \%$ \\
\hline $\mathrm{ClpC}$ & $\begin{array}{l}\text { ATP-dependent Clp protease, } \\
\text { ATP-binding subunit ClpC }\end{array}$ & gi | 446819870 & 5.51 & 90,968 & $11 \%$ \\
\hline Crr & $\begin{array}{c}\text { Glucose-specific } \\
\text { phosphotransferase enzyme IIA }\end{array}$ & gi | 261278560 & 4.64 & 63,097 & $15 \%$ \\
\hline DnaK & Chaperone protein DnaK & gi| 445956852 & 4.70 & 66,319 & $40 \%$ \\
\hline Eno & Enolase & gi| 447044501 & 4.58 & 47,115 & $43 \%$ \\
\hline FusA & Translation elongation factor $\mathrm{G}$ & gi|395759323 & 4.80 & 76,530 & $37 \%$ \\
\hline GroEL & Chaperonin protein, $60 \mathrm{kDa}$ & gi 657020658 & 4.59 & 57,537 & $16 \%$ \\
\hline $\operatorname{InfB}$ & Translation initiation factor IF-2 & gi| 445965771 & 5.09 & 77,795 & $18 \%$ \\
\hline Mqo2 & Malate quinone oxidoreductase 2 & gi | 447052792 & 6.12 & 55,978 & $13 \%$ \\
\hline PdhC & $\begin{array}{c}\text { Dihydrolipoyllysine-residue } \\
\text { acetyltransferase component of } \\
\text { pyruvate dehydrogenase complex }\end{array}$ & gi | 2499415 & 4.87 & 46,411 & $17 \%$ \\
\hline PflB & Formate acetyltransferase & gi| 446817402 & 5.31 & 84,822 & $24 \%$ \\
\hline Pgk & Phosphoglycerate kinase & gil 446997500 & 5.17 & 42,603 & $42 \%$ \\
\hline PheT & $\begin{array}{l}\text { phenylalanyl-tRNA synthase } \\
\text { subunit beta }\end{array}$ & gi $\mid 446831715$ & 4.71 & 88,838 & $19 \%$ \\
\hline Prs & $\begin{array}{l}\text { Ribose-phosphate } \\
\text { pyrophosphokinase }\end{array}$ & gi $\mid 446856516$ & 5.88 & 35,292 & $11 \%$ \\
\hline PtsI & $\begin{array}{l}\text { Phosphoenolpyruvate protein } \\
\text { phosphotransferase }\end{array}$ & gi | 446696933 & 4.82 & 34,929 & $11 \%$ \\
\hline Pyk & Pyruvate kinase & gi | 447155392 & 5.23 & 63,063 & $47 \%$ \\
\hline RnaseJ & Ribonuclease J2 & gi | 445974731 & 5.81 & 62,591 & $18 \%$ \\
\hline RplU & 50 S ribosomal protein L21 & gi $\mid 75530481$ & 9.78 & 11,309 & $50 \%$ \\
\hline RpoA & RNA polymerase, $\alpha$ chain & gi | 686416814 & 4.66 & 34,947 & $24 \%$ \\
\hline RpoB & RNA polymerase, $\beta$ chain & gil 686122810 & 4.91 & 133,152 & $19 \%$ \\
\hline SufB & Fe-S cluster assembly protein & gi | 446997144 & 5.08 & 52,498 & $19 \%$ \\
\hline Tig & Trigger factor & gi | 446049710 & 4.34 & 48,577 & $27 \%$ \\
\hline Tkt & Transketolase & gi | 446403587 & 5.00 & 72,212 & $34 \%$ \\
\hline TufA & Translation elongation factor $\mathrm{Tu}$ & gi| 446963310 & 4.77 & 43,077 & $56 \%$ \\
\hline
\end{tabular}

The identified proteins were classified by the annotation system of the Database for Annotation, Visualization and Integrated Discovery (DAVID) (version 6.7) [11]. Proteins were classified as four major pathways including transcription and translation, RNA degradation, the phosphotransferase system and glycolysis and the pentose phosphate pathway. In order to find relevant proteins among the multiple proteins obtained by proteomic analysis, 26 different proteins from Table 2 were subjected to the STRING database [12] for bioinformatics analysis. The STRING database integrates interaction data from several bioinformatics sources and provides information about physical and functional properties of known and predicted interactions of genes and proteins. As shown in Figure 4, each node represents a protein, and each edge represents an interaction. By mapping the affected proteins to central pathways, a number of proteins connected with each other in different metabolism pathways 
were found to be altered in MRSA by exposure to ursolic acid (Figure 4). The response to translational interpretation appeared to concentrate the cell's biosynthetic activities on the protein folding and degrading system (DnaK, GroEL, Eno) at the expense of metabolic functions (PflB, Pgk, PdhC and Tkt). In addition, those responses also triggered the induction of PtsI and Crr protein, the bacterial phosphoenolpyruvate sugar phosphotransferase system (PTS), to mediate the uptake and phosphorylation of carbohydrates and control metabolism in response to carbohydrate availability. The connection of AhpC with DnaK, ClpC and GroEL indicated that proteins involved in the oxidative response may also trigger the protein folding and degrading system.

Table 3. Changes in protein expression in MRSA following treatment with ursolic acid.

\begin{tabular}{|c|c|c|}
\hline Protein & Protein Name & Ratio $^{1}$ Treatment/Control \\
\hline \multicolumn{3}{|l|}{ Transcription } \\
\hline RpoB & RNA polymerase, $\beta$ chain & 1.042 \\
\hline RpoA & RNA polymerase, $\alpha$ chain & 1.123 \\
\hline \multicolumn{3}{|l|}{ Translation } \\
\hline FusA & Translation elongation factor $\mathrm{G}$ & 0.685 \\
\hline TufA & Translation elongation factor $\mathrm{Tu}$ & 0.958 \\
\hline $\operatorname{InfB}$ & Translation initiation factor IF-2 & 0.332 \\
\hline AlaS & Alanyl-tRNA synthase & 0.975 \\
\hline PheT & phenylalanyl-tRNA synthase subunit beta & 2.676 \\
\hline RplU & $50 S$ ribosomal protein L21 & 8.798 \\
\hline \multicolumn{3}{|c|}{ Protein folding and RNA degradation } \\
\hline ClpC & ATP-dependent Clp protease, subunit ClpC & 5.602 \\
\hline GroEL & Chaperonin protein, $60 \mathrm{kDa}$ & 1.387 \\
\hline Tig & Trigger factor & 1.368 \\
\hline DnaK & Chaperone protein DnaK & 1.282 \\
\hline Eno & Enolase & 1.387 \\
\hline RnaseJ & Ribonuclease J2 & 2.091 \\
\hline \multicolumn{3}{|c|}{ Glycolysis, TCA cycle and Pentose phosphate pathway } \\
\hline PflB & Formate acetyltransferase & 1.978 \\
\hline Pgk & Phosphoglycerate kinase & 0.386 \\
\hline PdhC & $\begin{array}{l}\text { Dihydrolipoyllysine-residue acetyltransferase } \\
\text { component of pyruvate dehydrogenase complex }\end{array}$ & 0.662 \\
\hline Pyk & Pyruvate kinase & 1.118 \\
\hline Tkt & Transketolase & 0.577 \\
\hline Mqo2 & Malate quinone oxidoreductase 2 & 4.11 \\
\hline \multicolumn{3}{|c|}{ Phosphotransferase system } \\
\hline PtsI & $\begin{array}{l}\text { Phosphoenolpyruvate-protein } \\
\text { phosphotransferase }\end{array}$ & 2.32 \\
\hline Crr & Glucose-specific phosphotransferase enzyme IIA & 1.671 \\
\hline \multicolumn{3}{|l|}{ Oxidative stress } \\
\hline AhpC & Alkyl hydroperoxide reductase subunit C & 6.074 \\
\hline \multicolumn{3}{|l|}{ Others } \\
\hline Adh & Alcohol dehydrogenase & 4.213 \\
\hline SufB & Fe-S cluster assembly protein & 0.235 \\
\hline AKRs & Glyoxal reductase & 0.708 \\
\hline Prs & Ribose-phosphate pyrophosphokinase & 0.869 \\
\hline AtpD & ATP synthase subunit beta & 1.473 \\
\hline Asp23 & alkaline shock protein 23 & 0.265 \\
\hline
\end{tabular}

${ }^{1}$ Ratio is defined as the \% volume of treatment $/ \%$ volume of control. The value $>1.5$ or $<0.67$ is recognized as a positive or negative regulation. 


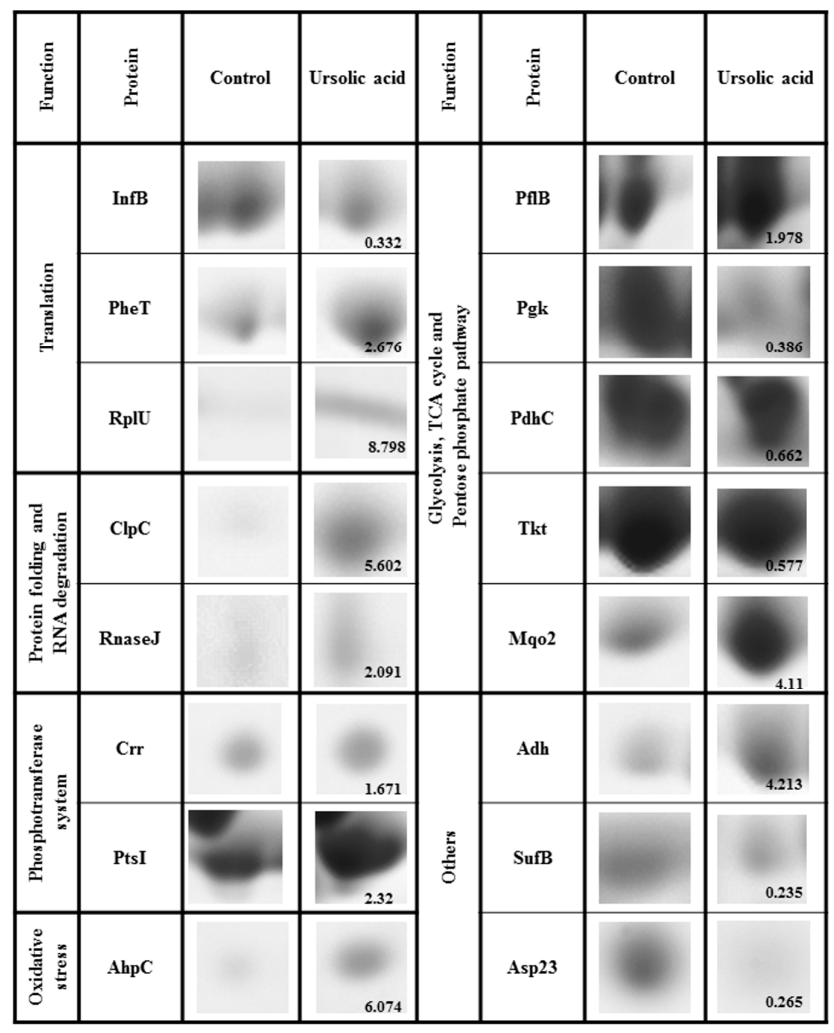

Figure 3. Details of 2D gels depicting 16 specific marker proteins for cell translation, protein folding and RNA degradation, the cell phosphotransferase system, oxidative stress, and the general cell metabolic pathway. Induction or reduction factor is presented in the lower right corner as the average over three replicates.

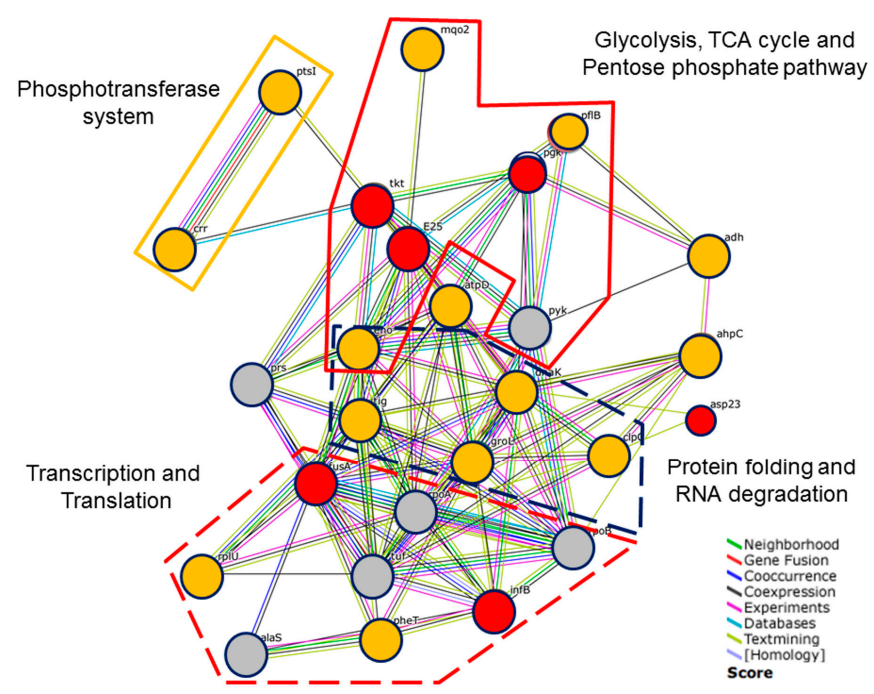

Figure 4. Differentially expressed proteins of ursolic acid-treated MRSA compared with controls. Dots in different colors represent repressed (red), induced (yellow) or no change (gray) in the presence of ursolic acid by quantitative proteomics. The identified proteins were classified by the annotation system Database for Annotation, Visualization and Integrated Discovery (DAVID) (version 6.7). The lines represent putative protein interactions recorded or predicted by STRING (version 10.0). 


\section{Discussion}

\subsection{Mode of Action I: Membrane Disruption}

Studies on the antimicrobial mechanisms of oleanolic acid and ursolic acid demonstrated that both of the pentacyclic triterpenoids can modulate resistance to two $\beta$-lactam antibiotics, ampicillin and oxacillin, in four bacterial pathogens [13]. Two 6-oxophenolic triterpenoids, zeylasteral and demethylzeylasteral, which were isolated from the root of Maytenus blepharodes, have antimicrobial activity against Bacillus subtilis [6]. Those triterpenoids block cell division by inhibiting DNA synthesis and macromolecular synthesis in Bacillus subtilis. In addition, the sesquiterpene farnesol can inhibit the recycling of the lipid carrier of the murein monomer precursor and can also reduce the secretion and activity of $\beta$-lactamase, thus contributing to the increased susceptibility to $\beta$-lactams in methicillin-resistant $S$. aureus [14]. In this study, the mode of action of ursolic acid appears to be the influence on the integrity of the bacterial membrane initially. The fact that ursolic acid acts to compromise the integrity of the bacterial membrane may explain why this compound has the synergistic ability to increase the antibacterial activity of antibiotics. In addition, there is evidence to suggest that bacteria are not resistant to membrane-active agents $[15,16]$. Thus, the membrane-perturbing ability of ursolic acid is also an advantage in restricting the selection of bacterial resistance.

\subsection{Mode of Action II: Translation Interruption}

A previous study indicated that both the transcriptional inhibitor and the various translational inhibitors all triggered an increased relative rate of synthesis of the components of the transcriptional and the translational machinery (RNA polymerase, elongation factors, ribosomal proteins, tRNA synthetases) in Haemophilus influenzae [10] and B. subtilis [9]. However, ursolic acid triggered a different way of decreasing the relative concentration of the elongation factor and $p \mathrm{I}$ changing in ribosomal proteins in this study. This implies that the signal for the regulation of RNA polymerase constituents as well as for ribosome subunits lies in the impairment of protein synthesis, regardless of whether it takes place at the level of mRNA synthesis or in ribosome function. The accumulation of mRNA and misfolded proteins leads to an induction of ribonuclease and chaperon subunits. Additionally, the Clp protein, comprising an ATPase specificity factor and a proteolytic domain, has been demonstrated to play a role in bacterial adaptation to multiple stresses by the degradation of accumulated misfolded proteins. In S. aureus, ClpC has been shown to regulate the TCA cycle, growth in recovery from the stationary phase and cell death, the oxidative stress response, autolysis, and DNA repair $[17,18]$. ClpC is a likely sensor of stress encountered during both environmental stress and infection [19]. Thus, ursolic acid may act as a protein synthesis inhibitor that interferes with translation accuracy-induced Clp proteins known to be induced by misfolded proteins.

\subsection{Mode of Action III: Metabolic Pathway Interaction}

Moreover, most of the metabolic enzymes involved in glycolysis displayed a decrease in their relative rate of synthesis upon treatment with ursolic acid. The response to protein synthesis inhibition appears to concentrate the cell's biosynthetic activities on the protein folding and degrading system at the expense of metabolic functions. Those responses may also trigger the induction of PtsI and Crr protein and the bacterial phosphoenolpyruvate sugar phosphotransferase system (PTS), to mediate the uptake and phosphorylation of carbohydrates and to control the metabolism in response to carbohydrate availability. Furthermore, alcohol dehydrogenase (Adh) is induced via NAD ${ }^{+}$ accumulation, which is a result caused by glycolysis repression. Glycolysis is an important process of ATP generation via the substrate level of phosphorylation. The breakdown of glucose generates more ATP in oxidative phosphorylation while the same monosaccharides produce only two net ATP in glycolysis [20]. During the repression of glycolysis, bacteria accumulated phosphoenol pyruvate 
(PEP) via enolase (Eno) and malate quinone oxidoreductase 2 (Mqo2) inductions. The formation of phosphoenol pyruvate (PEP) enables the synthesis of more ATP during oxidative phosphorylation.

\subsection{Mode of Action IV: Oxidative Stress Response}

Alkyl hydroperoxide reductase subunit $\mathrm{C}(\mathrm{AhpC})$ is the catalytic subunit responsible for the detoxification of reactive oxygen and facilitates the survival of pathogenic bacteria under environmental stress or during infection [21]. In Salmonella typhimurium, AhpC protects bacterial cells against reactive nitrogen intermediates [22]. Recently, a similar publication concluded that antibiotics pose an oxidative stress on the cells, and combating this stress is a general antibiotic response [23]. Ursolic acid may also elicit the oxidative response in MRSA via the AhpC induction.

As shown in Figure 5, the mechanism of ursolic acid against MRSA was illustrated. Initially, ursolic acid contacts MRSA and causes a destructive effect on the bacterial membrane. Later on, ursolic acid affects the proteins that are involved in the translation process with translational accuracy. The accumulation of mRNA and misfolded protein leads to an induction of ribonuclease and chaperon subunits. Furthermore, most of the metabolic enzymes involved in glycolysis display a decrease in their relative rate of synthesis upon treatment with ursolic acid. The repression of glycolysis and the pentose phosphate pathway induces the production of PtsI and Crr protein, the bacterial phosphotransferase system (PTS), to mediate the uptake and phosphorylation of carbohydrates and to control the metabolism in response to energy deficiency. Finally, ursolic acid elicits the oxidative response in MRSA. AhpC is induced in order to protect bacterial cells against reactive ursolic acid.

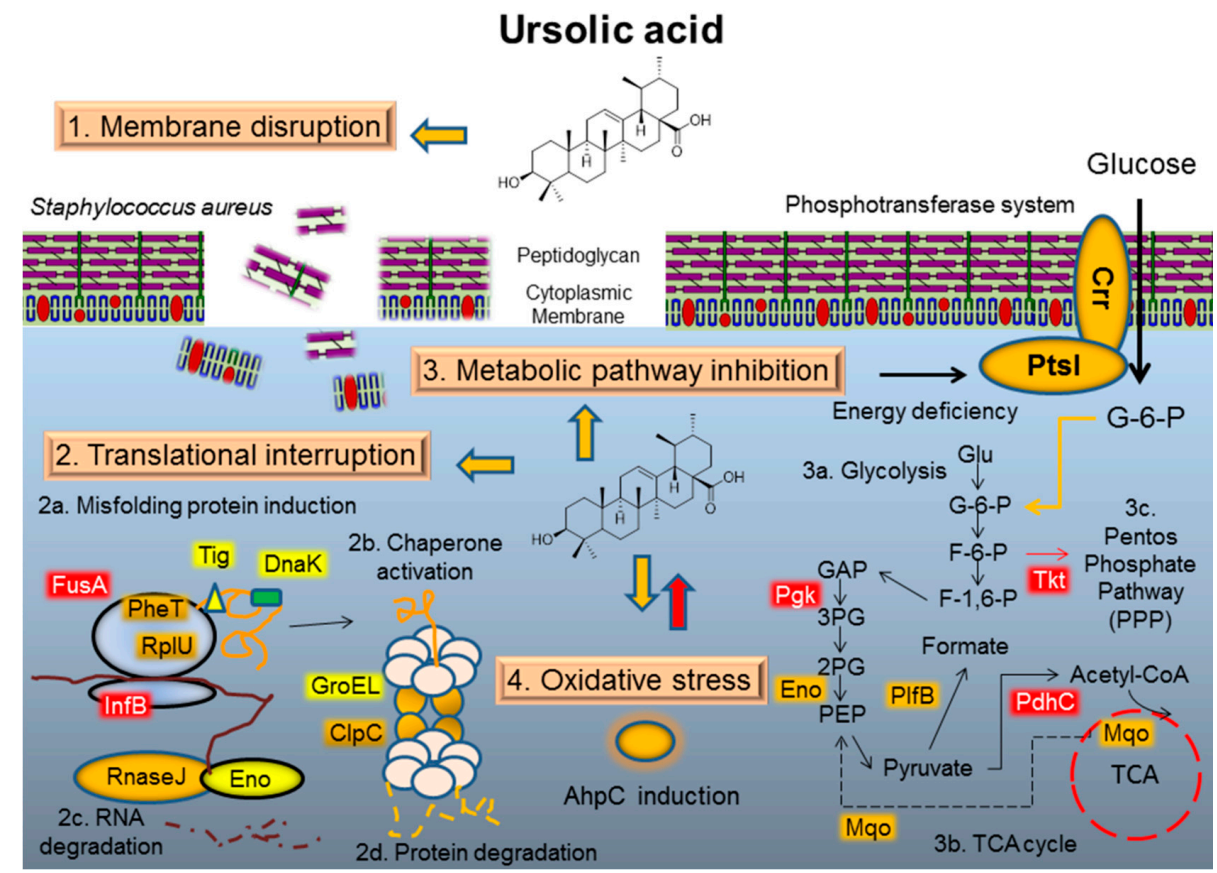

Figure 5. The hypothetical mechanism of ursolic acid against MRSA. Initially, ursolic acid contacts MRSA and causes a destructive effect on the bacterial membrane. Later on, ursolic acid affects the proteins that are involved in the translation process with translational accuracy. The accumulation of mRNA and misfolded protein leads to an induction of ribonuclease and chaperon subunits. Furthermore, most of the metabolic enzymes involved in glycolysis display a decrease in their relative rate of synthesis upon treatment with ursolic acid. The repression of glycolysis and the pentose phosphate pathway induces the production of PtsI and Crr protein, the bacterial phosphotransferase system (PTS), to mediate the uptake and phosphorylation of carbohydrates and to control the metabolism in response to energy deficiency. Finally, ursolic acid elicits the oxidative response in MRSA. AhpC is induced in order to protect bacterial cells against reactive ursolic acid. 


\section{Materials and Methods}

\subsection{Effects of Antimicrobial Agents on Bacterial and Mammalian Membranes Viability}

The effect of antibacterial compounds on the integrity of the staphylococcal membrane after one hour exposure was assessed using the BacLight ${ }^{\mathrm{TM}}$ assay according to the report previously [16]. Briefly, MRSA was exposed to a concentration of antibacterial agent equivalent to $4 \times$ MIC for 60 min at $37^{\circ} \mathrm{C}$. Mixture was centrifuged at $3000 \mathrm{~g}$ for $5 \mathrm{~min}$ and resuspended in PBS buffer. The MRSA was adjusted suspensions to $1 \times 10^{7} \mathrm{cfu} / \mathrm{mL}\left(\sim 0.15 \mathrm{OD}_{670}\right)$, mixed with reagents and incubated for $15 \mathrm{~min}$ in dark. Integrated intensities of the green (510-540 nm) and red (620-650 nm) emissions were acquired by fluorescence microplate reader. Bacteria with intact cell membranes stain fluorescent green, whereas bacteria with damaged membranes stain fluorescent red. The ratio of green to red fluorescence emission is proportional to the relative numbers of live bacteria and bacterial membranes viability.

The ability of compounds to damage mammalian membranes was examined by measuring the hemolysis of sheep erythrocytes [24]. Fresh whole sheep blood was treated with heparin, centrifuged at $1000 \mathrm{~g}$ for $10 \mathrm{~min}$ at $4{ }^{\circ} \mathrm{C}$, and discarded the supernatant. The erythrocyte pellet was washed and resuspended to $5 \% \mathrm{v} / \mathrm{v}$ in $10 \mathrm{mM}$ Tris- $\mathrm{HCl}$ buffer containing $0.85 \% \mathrm{NaCl}$. Erythrocytes were further diluted 10-fold in buffer, and exposed to a concentration of antibacterial agent equivalent to $4 \times \mathrm{MIC}$ for MRSA for $1 \mathrm{~h}$ at $37^{\circ} \mathrm{C}$. The hemolysis of sheep erythrocytes was measured at $\mathrm{OD}_{540}$ and the addition of $5 \%(w / v)$ sodium dodecyl sulfate (SDS) was defined as $100 \%$ hemolysis.

\section{2. $2 \mathrm{D} \mathrm{Gel} \mathrm{Electrophoresis} \mathrm{Analysis}$}

The bacteria were treated with ursolic acid (Sigma, St. Louis, MO, USA) at a concentration corresponding to $4 \times \mathrm{MIC}$ for $60 \mathrm{~min}$ according to previous reports [9,16]. This concentration decreases the growth rate of a mid-log-phase culture by $50 \%$ (Table 3 ) and could therefore be expected to trigger major changes in protein expression. Two-dimensional gel electrophoresis was performed by using the Ettan $^{\mathrm{TM}}$ IPGphor II Isoelectric Focusing system (GE Healthcare, Piscataway, NJ, USA) according to the instructions of the manufacturer. Protein samples $(300 \mu \mathrm{g})$ were separated by using IPG strips in $\mathrm{pH}$ range of 3-10. Isoelectric focusing was performed by using $7 \mathrm{M}$ urea, $2 \mathrm{M}$ thiourea, 4\% CHAPS and $40 \mathrm{mM}$ DTT with increasing voltage. Rod gels were soaked for $15 \mathrm{~min}$ at ambient temperature in equilibration buffer $(50 \mathrm{mM}$ Tris- $\mathrm{HCl}, \mathrm{pH} 8.8,6 \mathrm{M}$ urea, 30\% glycerol, 2\% SDS, $10 \mathrm{mg} / \mathrm{mL}$ DTT) and applied to a second dimension using a commercially available $12 \%$ Tris-Glycine SDS gel $(13 \mathrm{~cm} \times 13 \mathrm{~cm} \times 1.0 \mathrm{~mm})\left(\right.$ Pharmacia, Uppsala, Sweden) with an Ettan ${ }^{\mathrm{TM}}$ DALTsix Large Vertical System (GE Healthcare, Uppsala, Sweden). Image was scanned by ImageScanner ${ }^{\mathrm{TM}}$ (GE Healthcare, Uppsala, Sweden) and analyzed by ImageMaster ${ }^{\mathrm{TM}}$ 2D Platinum (GE Healthcare, Uppsala, Sweden).

\subsection{In-Gel-Preparation of Tryptic Peptides}

Coomassie-stained protein bands were excised from the gel and washed three times for $10 \mathrm{~min}$ with water. Reduction was performed with $100 \mathrm{mM} \mathrm{DTT} / 50 \mathrm{mM} \mathrm{NH} \mathrm{HCO}_{3}$ for $30 \mathrm{~min}$ at $56{ }^{\circ} \mathrm{C}$, and the proteins were subsequently alkylated with $55 \mathrm{mM}$ iodoacetamide in the dark for an additional $20 \mathrm{~min}$ at room temperature. Gel pieces were equilibrated twice with $1 \mathrm{~mL}$ of $50 \mathrm{mM} \mathrm{NH}_{4} \mathrm{HCO}_{3}$ ( $\mathrm{pH}$ 7.8) for $10 \mathrm{~min}$, shrunk with $1 \mathrm{~mL}$ of acetonitrile, rehydrated with $1 \mathrm{~mL}$ of $50 \mathrm{mM} \mathrm{NH}_{4} \mathrm{HCO}_{3}$ and finally shrunk again with acetonitrile. After air-drying, gel pieces were reswollen in a digestion buffer, containing $50 \mu \mathrm{L}$ of $50 \mathrm{mM} \mathrm{NH}_{4} \mathrm{HCO}_{3}$, and $0.05 \mathrm{mg}$ of trypsin (Promega, Madison, WI, USA) at $37{ }^{\circ} \mathrm{C}$ for $16 \mathrm{~h}$. Peptides were extracted by subsequent incubation for $30 \mathrm{~min}$ at room temperature with $50 \mathrm{mM} \mathrm{NH}_{4} \mathrm{HCO}_{3}, 0.1 \%$ TFA and finally $0.1 \%$ TFA/acetonitrile $(1: 2 v / v)$. 


\subsection{LC-MS/MS Analysis}

LC-MS/MS analysis was performed on an integrated nanoLC-MS/MS system (QSTAR XL, AB SCIEX, Framingham, MA, USA) comprising a LC Packings NanoLC system with an autosampler, and a QSTAR XL Q-Tof mass spectrometer (AB SCIEX, Framingham, MA, USA) fitted with nano-LC sprayer. Injected samples were first trapped and desalted on a LC-Packings PepMap ${ }^{\mathrm{TM}}$ C18 $\mu$-Precolumn ${ }^{\mathrm{TM}}$ Cartidge $(5 \mu \mathrm{m}, 30 \mu \mathrm{m}$ inner diameter $\times 5 \mathrm{~mm}$, ThermoFisher Scientific Inc., Waltham, MA, USA). Peptides were separated on an analytical LC-Packings PepMap C18column $(3 \mu \mathrm{m}, 75 \mathrm{~mm}$ inner diameter $\times 15 \mathrm{~cm}$, ThermoFisher Scientific Inc.) connected inline to the mass spectrometer, using a $45 \mathrm{~min}$ gradient of $5 \%$ to $60 \%$ acetonitrile in $0.1 \%$ formic acid. Data of MS/MS were fully automated and synchronized with AnalystQS (version 1.0) software. For protein identification analysis, the one second survey scans were acquired over the mass range $m / z$ 400-1600 and a maximum of 10 concurrent MS/MS acquisitions could be triggered for $2+, 3+$ and $4+$ charged precursors detected at an intensity above the predefined threshold. The peak list files were used to query the NCBI database using the Mascot for web search (Matrix Science, Boston, MA, USA).

\subsection{Data Analysis}

The annotation system, Database for Annotation, Visualization and Integrated Discovery (DAVID) (version 6.7) [11], was used for analysis of differentially expressed proteins by Gene Ontology assignment. Identified proteins were uploaded into the DAVID functional annotation tool and compared to the proteome background of S. aureus. The relationship between differentially expressed proteins in ursolic acid treated MRSA and their interaction with other proteins were analyzed using STRING database 10.0 [12]. All statistical analyses were conducted using SPSS 13.0. All results have been expressed as average mean \pm standard deviation (S.D.) values. ANOVA was used to evaluate differences and a $p$ value of $<0.05$ was considered significantly. Turkey's multiple range test was also used to evaluate the means. Different letters represent values that were significantly different at $\alpha=0.05$ level.

\section{Conclusions}

In this study, the mode of action of ursolic acid appears to be the influence on the integrity of the bacterial membrane initially, followed by the inhibition of protein synthesis and the metabolic pathway. These results suggest that the proteomics approach gives new insights into the bacterial response toward antibacterial compounds with unknown mechanisms of action, which should prove useful in the process of antibiotic drug discovery. The pleiotropic effects of ursolic acid against MRSA make it a promising antibacterial agent in pharmaceutical research.

Acknowledgments: This work was financially supported by research grants from the Ministry of Science and Technology (MOST 103-2621-B-039-002-MY2 and MOST 104-2811-B-039-019) in Taiwan awarded to C.-H.C. Technical assistance with chemical data analyses from the Proteomics Research Core Laboratory, Office of Research \& Development at China Medical University and Instrument Analysis Centers at the National Chung-Hsing University is greatly appreciated.

Author Contributions: C.-M.W. conceived and designed the experiments; C.-M.W., Y.-L.J., and S.-J.T. performed the experiments; C.-M.W. analyzed the data; C.-H.C. contributed reagents/materials/analysis tools; C.-M.W. and C.-H.C. wrote the paper. All authors read and approved the final manuscript.

Conflicts of Interest: The authors declare no conflict of interest.

\section{References}

1. Shanmugam, M.K.; Nguyen, A.H.; Kumar, A.P.; Tan, B.K.; Sethi, G. Targeted inhibition of tumor proliferation, survival, and metastasis by pentacyclic triterpenoids: Potential role in prevention and therapy of cancer. Cancer Lett. 2012, 320, 158-170. [CrossRef] [PubMed] 
2. Way, T.D.; Tsai, S.J.; Wang, C.M.; Ho, C.T.; Chou, C.H. Chemical constituents of Rhododendron formosanum show pronounced growth inhibitory effect on non-small-cell lung carcinoma cells. J. Agric. Food Chem. 2014, 62, 875-884. [CrossRef] [PubMed]

3. Baliga, M.S. Review of the phytochemical, pharmacological and toxicological properties of Alstonia scholaris Linn. R. Br (Saptaparna). Chin. J. Integr. Med. 2012, 18. [CrossRef] [PubMed]

4. El-Askary, H.I.; El-Olemy, M.M.; Salama, M.M.; Sleem, A.A.; Amer, M.H. Bioguided isolation of pentacyclic triterpenes from the leaves of Alstonia scholaris (Linn.) R. Br. growing in Egypt. Nat. Prod. Res. 2012, 26, 1755-1758. [CrossRef] [PubMed]

5. Wang, C.-M.; Chen, H.-T.; Wu, Z.-Y.; Jhan, Y.-L.; Shyu, C.-L.; Chou, C.-H. Antibacterial and synergistic activity of pentacyclic triterpenoids isolated from Alstonia scholaris. Molecules 2016, 21, 139. [CrossRef] [PubMed]

6. de Leon, L.; Beltran, B.; Moujir, L. Antimicrobial activity of 6-oxophenolic triterpenoids. Mode of action against Bacillus subtilis. Planta Med. 2005, 71, 313-319. [CrossRef] [PubMed]

7. Katerere, D.R.; Gray, A.I.; Nash, R.J.; Waigh, R.D. Antimicrobial activity of pentacyclic triterpenes isolated from African Combretaceae. Phytochemistry 2003, 63, 81-88. [CrossRef]

8. Hecker, M.; Reder, A.; Fuchs, S.; Pagels, M.; Engelmann, S. Physiological proteomics and stress/starvation responses in Bacillus subtilis and Staphylococcus aureus. Res. Microbiol. 2009, 160, 245-258. [CrossRef] [PubMed]

9. Bandow, J.E.; Brotz, H.; Leichert, L.I.; Labischinski, H.; Hecker, M. Proteomic approach to understanding antibiotic action. Antimicrob. Agents Chemother. 2003, 47, 948-955. [CrossRef] [PubMed]

10. Evers, S.; Di Padova, K.; Meyer, M.; Langen, H.; Fountoulakis, M.; Keck, W.; Gray, C.P. Mechanism-related changes in the gene transcription and protein synthesis patterns of Haemophilus influenzae after treatment with transcriptional and translational inhibitors. Proteomics 2001, 1, 522-544. [CrossRef]

11. Dennis, G., Jr.; Sherman, B.T.; Hosack, D.A.; Yang, J.; Gao, W.; Lane, H.C.; Lempicki, R.A. DAVID: Database for annotation, visualization, and integrated discovery. Genome Biol. 2003, 4, P3. [CrossRef]

12. Szklarczyk, D.; Franceschini, A.; Wyder, S.; Forslund, K.; Heller, D.; Huerta-Cepas, J.; Simonovic, M.; Roth, A.; Santos, A.; Tsafou, K.P.; et al. STRING v10: Protein-protein interaction networks, integrated over the tree of life. Nucleic Acids Res. 2015, 43, D447-D452. [CrossRef] [PubMed]

13. Kurek, A.; Nadkowska, P.; Pliszka, S.; Wolska, K.I. Modulation of antibiotic resistance in bacterial pathogens by oleanolic acid and ursolic acid. Phytomedicine 2012, 19, 515-519. [CrossRef] [PubMed]

14. Kuroda, M.; Nagasaki, S.; Ohta, T. Sesquiterpene farnesol inhibits recycling of the C55 lipid carrier of the murein monomer precursor contributing to increased susceptibility to beta-lactams in methicillin-resistant Staphylococcus aureus. J. Antimicrob. Chemother. 2007, 59, 425-432. [CrossRef] [PubMed]

15. Hurdle, J.G.; O’Neill, A.J.; Chopra, I.; Lee, R.E. Targeting bacterial membrane function: An underexploited mechanism for treating persistent infections. Nat. Rev. Microbiol. 2011, 9, 62-75. [CrossRef] [PubMed]

16. Ooi, N.; Miller, K.; Hobbs, J.; Rhys-Williams, W.; Love, W.; Chopra, I. XF-73, a novel antistaphylococcal membrane-active agent with rapid bactericidal activity. J. Antimicrob. Chemother. 2009, 64, 735-740. [CrossRef] [PubMed]

17. Chatterjee, I.; Becker, P.; Grundmeier, M.; Bischoff, M.; Somerville, G.A.; Peters, G.; Sinha, B.; Harraghy, N.; Proctor, R.A.; Herrmann, M. Staphylococcus aureus $\mathrm{ClpC}$ is required for stress resistance, aconitase activity, growth recovery, and death. J. Bacteriol. 2005, 187, 4488-4496. [CrossRef] [PubMed]

18. Michel, A.; Agerer, F.; Hauck, C.R.; Herrmann, M.; Ullrich, J.; Hacker, J.; Ohlsen, K. Global regulatory impact of ClpP protease of Staphylococcus aureus on regulons involved in virulence, oxidative stress response, autolysis, and DNA repair. J. Bacteriol. 2006, 188, 5783-5796. [CrossRef] [PubMed]

19. Frees, D.; Chastanet, A.; Qazi, S.; Sorensen, K.; Hill, P.; Msadek, T.; Ingmer, H. Clp ATPases are required for stress tolerance, intracellular replication and biofilm formation in Staphylococcus aureus. Mol. Microbiol. 2004, 54, 1445-1462. [CrossRef] [PubMed]

20. Flamholz, A.; Noor, E.; Bar-Even, A.; Liebermeister, W.; Milo, R. Glycolytic strategy as a tradeoff between energy yield and protein cost. Proc. Natl. Acad. Sci. USA 2013, 110, 10039-10044. [CrossRef] [PubMed]

21. Wang, H.W.; Chung, C.H.; Ma, T.Y.; Wong, H.C. Roles of alkyl hydroperoxide reductase subunit C (AhpC) in viable but nonculturable Vibrio parahaemolyticus. Appl. Environ. Microbiol. 2013, 79, 3734-3743. [CrossRef] [PubMed] 
22. Chen, L.; Xie, Q.W.; Nathan, C. Alkyl hydroperoxide reductase subunit C (AhpC) protects bacterial and human cells against reactive nitrogen intermediates. Mol. Cell 1998, 1, 795-805. [CrossRef]

23. Kohanski, M.A.; Dwyer, D.J.; Hayete, B.; Lawrence, C.A.; Collins, J.J. A common mechanism of cellular death induced by bactericidal antibiotics. Cell 2007, 130, 797-810. [CrossRef] [PubMed]

24. Oliva, B.; Miller, K.; Caggiano, N.; O’Neill, A.J.; Cuny, G.D.; Hoemarm, M.Z.; Hauske, J.R.; Chopra, I. Biological properties of novel antistaphylococcal quinoline-indole agents. Antimicrob. Agents Chemother. 2003, 47, 458-466. [CrossRef] [PubMed]

Sample Availability: Sample Availability: Samples of the compounds are available from the authors.

(C) 2016 by the authors; licensee MDPI, Basel, Switzerland. This article is an open access article distributed under the terms and conditions of the Creative Commons Attribution (CC-BY) license (http://creativecommons.org/licenses/by/4.0/). 